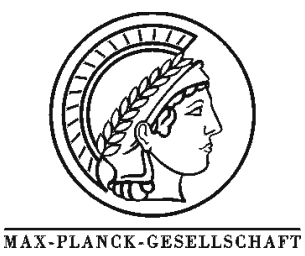

\title{
Alcohol selective oxidation over modified foam-silver catalysts
}

\author{
A.N. Pestryakov ${ }^{\mathrm{a}, *}$, V.V. Lunin ${ }^{\mathrm{b}}$, N.E. Bogdanchikova ${ }^{\mathrm{c}}$, \\ V.P. Petranovskii ${ }^{\mathrm{c}}$, A. Knop-Gericke ${ }^{\mathrm{a}}$ \\ ${ }^{a}$ Department of Inorganic Chemistry, Fritz-Haber-Institute of the MPG, Faradayweg 4-6, 14195 Berlin, Germany \\ ${ }^{\mathrm{b}}$ Chemistry Department, Moscow State University, Moscow 119899 Russia \\ ${ }^{c}$ Centro de Ciencias de la Materia Condensada, UNAM, Ensenada 22800, Mexico
}

${ }^{*}$ Corresponding author: e-mail alex@fhi-berlin.mpg.de, phone +49 308413 5408, fax +49 3084134401

Received 07 February 2003; accepted 05 May 2003

\begin{abstract}
Catalysts based on silver supported on foam ceramics and modified by $\mathrm{Zr}$, Ce and La oxides have been studied in the process of partial oxidation of methanol to formaldehyde. The foam catalysts exhibit high catalytic, mechanical and gas-dynamic properties exceeding the characteristics of conventional crystalline and supported silver samples. Modifying additives of $\mathrm{Zr}$ and Ce oxides raise activity and selectivity of the supported foam-silver catalyst as well as its stability during the prolonged functioning. The modifiers change the electronic state and redox properties of silver, the metal dispersivity, surface diffusion and aggregation of silver during the long-term service.
\end{abstract}

Keywords: Silver; Foam catalysts; Methanol oxidation; UV-visible spectroscopy

\section{Introduction}

Catalysts based on foam metals and foam ceramics exhibit high efficiency in processes of partial and complete oxidation of different organic compounds [1-12]. Foam materials have uniform cellular structure with anisotropy of mechanical and gas-dynamic properties: an average diameter of the elementary cell $-0.5-5.0 \mathrm{~mm}$; porosity - 80-98\%; volume density $-0.1-0.5 \mathrm{~g} / \mathrm{cm}^{3}$. The last parameters were important for producing catalysts based on foam metals (especially, noble metals) since it enables their material requirements and, consequently, production cost to be greatly reduced.

Our previous studies revealed that catalysts based on the foam materials are very promising for usage in the processes of partial oxidation of alcohols to aldehydes [8-12]. Thus, bulk foam silver and supported foam $\mathrm{Ag} /$ ceramics catalysts have physicochemical and catalytic properties exceeding the characteristics of the traditional crystalline silver and supported $\mathrm{Ag} /$ pumice catalysts [8-9]. The supported $\mathrm{Ag} /$ ceramics catalysts have lower silver percentage (and, consequently, cost price) as compared to bulk foam silver, however, after prolonged operation they are partly deactivated because of the metal aggregation and the support carbonization.

The aim of the present study is to improve the catalytic properties of silver catalysts supported on foam ceramics using modifying additives of metal oxides in the methanol partial oxidation and to investigate the influence of the promoters on electronic state of silver.

\section{Experimental}

The catalyst samples were prepared by supporting silver $(10 \%$-wt.) on the modified foam ceramics from aqueous solution of the metal nitrates by chemical reduction with hydrazine sulphate. Modifying additives (1\%-wt.) of $\mathrm{Zr}$, Ce and $\mathrm{La}$ oxides were supported on the pure carrier by impregnation from the metal nitrate solutions followed by thermal decomposition of the nitrites to oxides at $300^{\circ} \mathrm{C}$ for $2 \mathrm{~h}$.

The catalysts were tested in the catalytic methanol oxidation system under operating conditions close to the industrial ones: $\mathrm{T}=550-650^{\circ} \mathrm{C}$, methanol concentration $70 \%$, 
ratio $\mathrm{O}_{2} / \mathrm{CH}_{3} \mathrm{OH}=0.35$, methanol load $100 \mathrm{~g} /\left(\mathrm{cm}^{2} . \mathrm{h}\right)$, air flow rate $2.8 \mathrm{ml} / \mathrm{s}$, composition of air-vapor mixture $37.5 \%$ $\mathrm{CH}_{3} \mathrm{OH}, 13.5 \% \mathrm{O}_{2}, 49 \% \mathrm{~N}_{2}$.

For comparison, bulk foam silver catalyst was tested under the same conditions. Gaseous products and formaldehyde were analyzed using chromatographic and titrimetric methods, respectively.

The specific surface area of the foam ceramics was 0.3 $\mathrm{m}^{2} / \mathrm{g}$, of bulk foam silver $-0.1 \mathrm{~m}^{2} / \mathrm{g}$. The difference in the specific surface of the samples does not influence significantly their catalytic properties, because the process occurs in an outward diffusion mode.

Diffuse reflectance UV-Visible spectra were taken on a Varian Cary 300 spectrometer equipped with a standard sphere using $\mathrm{BaSO}_{4}$ as a reference.

\section{Results and Discussion}

Our previous studies revealed that the selectivity of foam silver catalysts in alcohol oxidation accounted for 90$96 \%$, that exceeded the one of conventional crystalline silver catalyst by $2-5 \%$ and commercial supported $40 \mathrm{wt} . \%$ $\mathrm{Ag} /$ pumice catalyst by 5-7\% [8-9]. This effect is caused by high gas permeability of the foam samples. Contrary to the traditional crystal and supported catalysts, foam silver did not sinter at high temperature as the individual parts of the active surface are not in contact with each other. This allows using the foam catalysts both in "soft" and in "hard" operating mode.

Catalytic properties of bulk foam silver depend strongly on the foam cell diameter [8]. Recent tests revealed that for supported foam samples this correlation differs from the one of bulk metal foam (Fig 1).

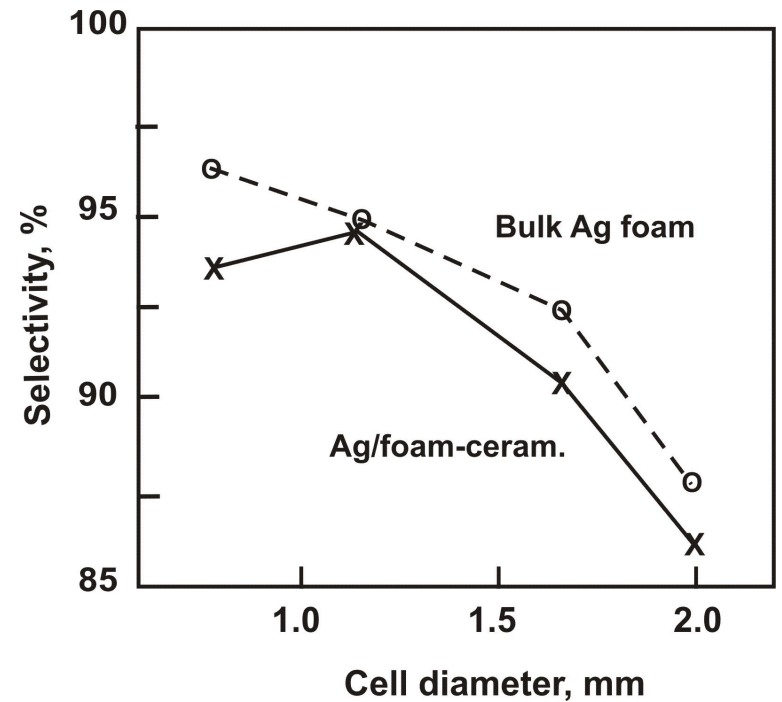

Figure 1. Selectivity of foam-silver samples with different cell size in methanol oxidation.

On the large-cell catalyst homogeneous deep oxidation of the product takes place in the cell void volume, which results in selectivity decreasing. Moreover, largecellular metal blocks have heat capacity not sufficient for upkeep the adiabatic mode of the process. However, supported fine-cellular sample has worse catalytic properties as compared to the bulk one. It is caused by thicker bridges of the cellular frame of the foam ceramics that leads to less gas permeability. Thus, for supported foam catalyst the optimal cell diameter is about $1.0-1.2 \mathrm{~mm}$.

Chemical modification of catalysts by different compounds is one of the most effective methods to improve their characteristics. Catalytic properties of the modified foam-ceramic silver samples are presented in the Fig. 2. The experiments showed that additives of $\mathrm{Zr}$ and $\mathrm{Ce}$ oxides raise

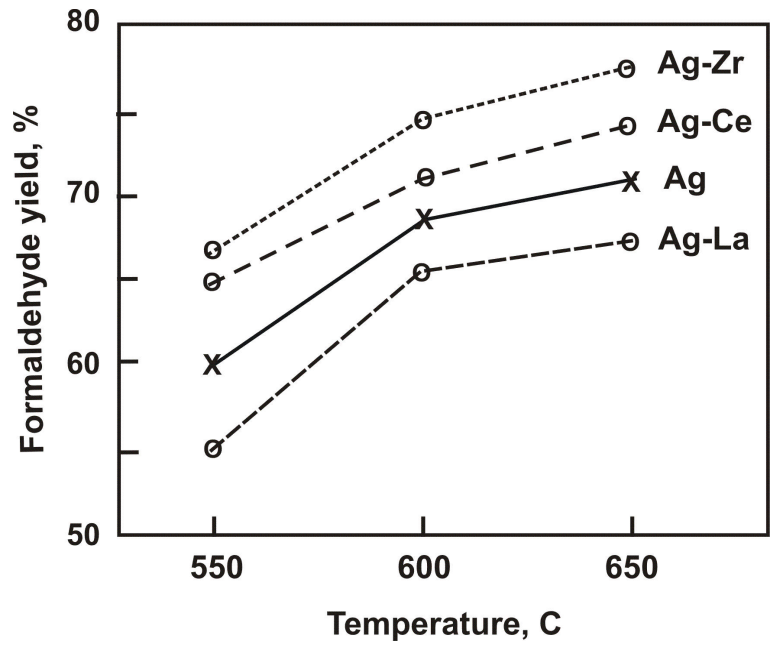

Figure 2. Catalytic properties of $\mathrm{Ag} /$ foam-ceramics in methanol oxidation.

the activity and selectivity of silver catalysts in methanol partial oxidation. Sample modified by La oxide exhibited less selectivity as compared to the unmodified catalyst. Tests of the modified foam support (without silver) disclosed that the modifiers are inactive in this process, and so, their intrinsic catalytic properties can not explain the observed effects.

Changes in the metal dispersivity on the surface of the modified support seem to be one of the reasons of the observed effects. Supported catalysts for formaldehyde synthesis have low surface area $\left(0.5-1 \mathrm{~m}^{2} / \mathrm{g}\right)$ and high metal percentage, therefore, average size of the metal particles is rather big - more then $1000 \mathrm{~nm}$. However, our previous studies disclosed that even at high silver content a major part of support surface $(20-40 \%)$ is not covered with the metal film and big aggregates but contains high-dispersed $\mathrm{Ag}^{+}$and $\mathrm{Ag}_{\mathrm{n}}{ }^{\delta+}$ particles [13-15]. These states experience direct effect of the support and modifiers.

Indeed, photomicrographs and oxygen adsorption measurements show that portion of dispersed silver states on the surface of the modified foam-ceramic support is $1.5-2$ times higher than in the unmodified sample. This is associated with the strong metal-support interaction. High-charged $\mathrm{Ce}^{3+}, \mathrm{Ce}^{4+}, \mathrm{Zr}^{4+}, \mathrm{La}^{3+}$ ions generate a large amount of sites for silver stabilization on the support surface. Also these sites retard the surface diffusion and aggregation of the metal during the process of methanol oxidation. Long-term tests revealed that the sample modified by $\mathrm{ZrO}_{2}$ exhibits 
stable activity, while the index of the unmodified sample decreases because of aggregation of the silver particles and carbonization of the uncovered support surface (Fig. 3).

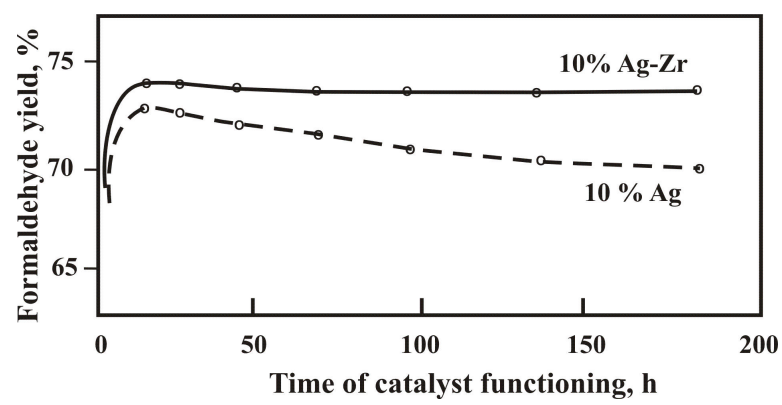

Figure 3. Catalytic properties of $\mathrm{Ag} /$ foam-ceramics in longterm tests $\left(650^{\circ} \mathrm{C}\right)$.

However, variations in the metal dispersivity in the modified samples are not unique reason of differences in their catalytic properties. Firstly, at high temperatures (500$700^{\circ} \mathrm{C}$ ) the diffusion of gas molecules controls the rate of the process, whereas the metal particle size influence only the rate of surface reaction at kinetic ranges of temperatures $\left(<300^{\circ} \mathrm{C}\right)$. In our process deceleration of surface diffusion of the silver particles during the reaction plays more important role than the metal dispersivity. Secondly, additive of lanthanum oxide also raises the metal dispersion, however, selectivity of Ag-La sample drops. It means that the modifiers exert a direct effect on the state of silver active sites.

Previous studies revealed stabilizing effect of $\mathrm{Ce}$ and $\mathrm{Zr}$ oxides on ionic states of silver $\left(\mathrm{Ag}^{+}, \mathrm{Ag}_{\mathrm{n}}{ }^{\delta+}\right)$ on the surface of the modified supports [13-16]. In contrast, additives of $\mathrm{La}_{2} \mathrm{O}_{3}$ reduce the amount of ions and their effective charge. We suggested univalent ions $\mathrm{Ag}^{\delta+}$ to be active states of silver in alcohol partial oxidation [13-14]. Surface electronic states of silver may influence certain forms of adsorbed oxygen (surface, subsurface), which are responsible (according to Refs. [17-18]) for different directions of the oxidation processes on silver. It is obvious that additives of $\mathrm{Ce}$ and $\mathrm{Zr}$ oxides stabilize ionic states of silver on the surface of foam-ceramic support. This is confirmed by the method of UV-visible spectroscopy of diffuse reflectance.

The diffuse reflectance spectrum of unmodified $\mathrm{Ag} /$ ceramics sample contains five pronounced absorption bands - 250, 280, 315, 380 and $460 \mathrm{~nm}$ (Fig. 4). According to our previous studies [14-16] and literature data [19-21] the signals at 250, 280 and $380 \mathrm{~nm}$ belong to charge transfer bands of ions $\mathrm{Ag}^{+}$and small charged clusters $\operatorname{Ag}_{\mathrm{n}}{ }^{\delta+}(\mathrm{n}<10)$. The strong signal at $315 \mathrm{~nm}$ is attributed to the intrinsic photoeffect in silver films and big particles. The absorption band at $460 \mathrm{~nm}$ corresponds to the plasmon resonance in metallic $\mathrm{Ag}_{\mathrm{m}}$ particles.

In the spectra of Ag-Ce and Ag-Zr samples signals corresponding to silver ions and charged clusters $\mathrm{Ag}_{\mathrm{n}}{ }^{\delta+}$ are significantly more intensive. In the spectrum of Ag-La these bands are similar to the ones for the unmodified sample, however, signal at $460 \mathrm{~nm}$ is much more pronounced. It

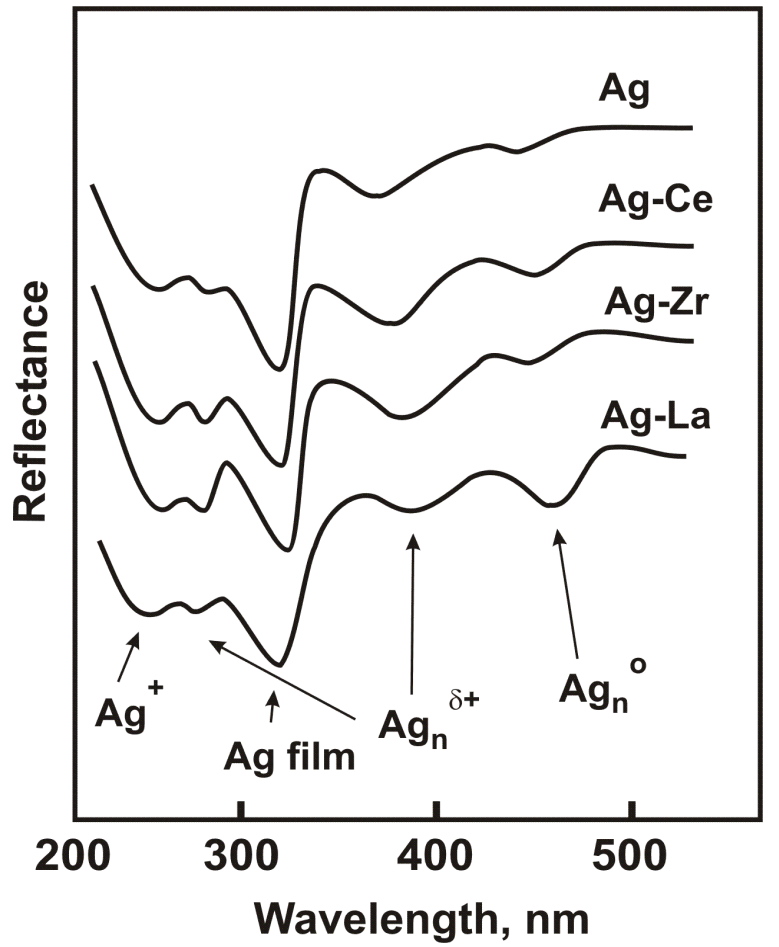

Figure 4. UV-visible spectra of diffuse reflectance of the modified Ag/foam-ceramics catalysts used in methanol oxidation process.

means that Ag-La catalyst contains more dispersed but uncharged states of silver. Hence, modifiers stabilizing ionic states of silver improve its the catalytic properties in methanol partial oxidation.

\section{Conclusions}

1. Catalysts based on silver supported on foam ceramics are promising for the usage in the process of partial oxidation of methanol to formaldehyde due to their high catalytic, mechanical and gas-dynamic properties.

2. Modifying additives of $\mathrm{Zr}$ and $\mathrm{Ce}$ oxides raise activity and selectivity of the supported foam-silver catalyst as well as its stability during the prolonged functioning.

3. The effect of modifiers on silver catalyst is versatile and includes variations in electronic state and redox properties of silver; change of the metal dispersivity, surface diffusion and aggregation of silver during the long-term service.

\section{Acknowledgments}

The authors acknowledge funding for this research by and RF President grant No 02-15-99360, Russia; CONACYT, Mexico, grant No 31366-U; and PAPIITUNAM, Mexico, grant No 115800 . 


\section{References}

1. P.S. Liu and K.M. Liang, J. Mater. Sci., 36 (2001) 5059.

2. J. Banhart, Progress in Materials Science, 46 (2001) 559.

3. C.S.Y. Jee, N. Ozguven, Z.X. Guo, J.R.G. Evans, Metal. Mater. Trans. B, 31 (2000) 1345.

4. A.N. Pestryakov, A.A. Fyodorov, V. A. Shurov, M.S. Gaisinovich, I.V. Fyodorova, React. Kinet. Catal. Lett. 53 (1994) 347.

5. A.N. Pestryakov, A.A. Fyodorov, M.S. Gaisinovich, V.P. Shurov, I.V. Fyodorova, T.A. Guba ydulina, React. Kinet. Catal. Lett. 54 (1995) 167.

6. A.N. Pestryakov, E.N. Yurchenko, A.E. Feofilov, Catal. Today 29 (1996) 67.

7. O.Y. Podyacheva, A.A. Ketov, Z.R. Ismagilov, V.A. Ushakov, A. Bos, H.J. Veringa, React. Kinet. Catal. Lett., 60 (1997) 243

8. A.N. Pestryakov, V.V. Lunin, N.E. Bogdanchikova, V.P. Petranovskii, A.Knop-Gericke, Catal. Commun., 2003, in press.

9. A.N. Pestryakov, V.V. Lunin, A.N. Devochkin, L.A. Petrov, N.E. Bogdanchikova, V.P. Petranovskii, Appl. Catal. A. 227 (2002) 127.

10. A.N. Pestryakov, A.N. Devochkin, React. Kinet. Catal. Lett. 52 (1994) 429.

11. A.N. Devochkin, A.N. Pestryakov, L.N. Kurina, React. Kinet. Catal. Lett. 47 (1992) 13.

12. A.N. Pestryakov, A.A. Fyodorov, A.N. Devochkin, J. Advanced Materials 5 (1994) 471.

13. A.N. Pestryakov, A.A. Davydov, Appl. Catal. A. 120 (1994) 7.

14. A.N. Pestryakov, Catal. Today 28 (1996) 239.

15. A.N.Pestryakov, A.A. Davydov, Kinet. Catal. 37 (1996) 923.

16. A.N. Pestryakov, A.A. Davydov, J. Electron Spectr. 74 (1995) 195.

17. V.I. Bukhtiyarov, M. Hävecker, V.V. Kaichev, A. Knop-Gericke, R.M. Mayer, R. Schlögl, Nucl. Instr. Meth. A. 470 (2001) $302-305$

18. V.I. Bukhtiyarov, M. Hävecker, V.V. Kaichev, A. Knop-Gericke, R.W. Mayer, R. Schlögl, Catal. Lett. 74 (2001) 121 -125

19. N.E. Bogdanchikova, M.N. Dulin, A.A. Davydov, V.F. Anufrienko, React. Kinet. Catal. Lett. 41 (1990) 73

20. N.E. Bogdanchikova, A.I. Boronin, V.I. Buhtiyarov, Kinet. Catal. 31 (1990) 145.

21. Ye.Yu. Batyan, G.A. Branitskii, N.E. Bogdanchikova, M.N. Dulin, Rus. J. Phys. Chem. 68 (1994) 448. 